\title{
Normal and oblique penetration of woven CFRP laminates by a high velocity steel sphere
}

PJ Hazell*, G Kister, C Stennett, P Bourque, G Cooper

Cranfield University, DCMT, Shrivenham, Swindon, Wiltshire, SN6 8LA

\begin{abstract}
In this research two thicknesses of a woven CFRP laminate have been subjected to impact by a steel sphere in a velocity regime ranging from $170 \mathrm{~m} / \mathrm{s}$ to $374 \mathrm{~m} / \mathrm{s}$. Impact and penetration of targets at normal and oblique incidence were studied using high speed video. For the normal incidence targets at the higher velocities of impact, a conical mass of laminate was ejected ahead of the projectile. Furthermore, despite the energy transferred to the plate increasing with impact energy, the degree of delamination in the thicker targets decreased indicating a change in projectile penetration mechanism. Eventually, the degree of delamination in the thicker targets appeared to approach an asymptotic level whereas for the thinner targets the degree of delamination appeared constant regardless of impact energy. For oblique targets more of the kinetic energy was transferred from the projectile when compared to the same thickness of target that had been subjected to a normal incidence impact. However, this was merely due to a geometrical effect. Further, thicker panels appeared to behave more efficiently by absorbing more kinetic energy per effective linear thickness at the lower impact energies
\end{abstract}


where petalling is a dominant factor in the penetration. This advantage appeared to disappear as the impact energy was increased.

Keywords: A. Carbon fibre, B. Impact behaviour, B. Delamination C. Damage mechanics. 


\section{INTRODUCTION}

The response of carbon fibre reinforced polymer (CFRP) materials to low velocity impact damage, where the concern has been for objects dropped onto panels at a few metres per second, has been extensively studied [1-6] However, there are relatively few papers concerned with the impact response of CFRP panels where the projectile approaches and exceeds that of the ballistic velocity regime. Cantwell and Morton [7] have shown that the response of a CFRP panel to these two very different loading regimes is quite different. On the one hand, for low velocity impact, the size and shape of the panel determine its energy absorbing capability. Whereas on the other hand, high velocity projectiles induce a localised response in the target that does not depend on the areal size of the target.

Hammond et al [8] studied the response of relatively thin (1.8-2.5 mm) CFRP panels of different symmetrical lay-ups struck by a $12.7 \mathrm{~mm}$ steel projectile that had an average velocity of $474 \mathrm{~m} / \mathrm{s}$. Here they showed that microstructural damage mechanisms were similar regardless of lay-up with the major differences being the volume over which the damage was spread. Tanabe et al [9] tested CFRPs of 2 mm thickness that were made with different interfacial strengths, properties and sequences of reinforcing fibres. Again the sequences of the lay-ups were symmetrical. These were struck by 5 -mm steel spheres in the velocity range of $150-314 \mathrm{~m} / \mathrm{s}$. Their experimental work showed that at $150 \mathrm{~m} / \mathrm{s}$, a weak interface resulted in higher energy absorption. Interestingly, they also observed that there is no clear difference in the ballistic performance of cross-ply specimens and specimens consisting of woven cloth. Further work by Tanabe and co-workers [10] have 
shown that the interfaces between fibre lay-ups are particularly important. They measured the stress and strain using PVDF stress gauges and constantan strain gauges to assess the effect of reinforcing fibres. They showed that the maximum stress generated depended on the reinforcing fibres whereas weak interfaces seemed to result in low stresses and strains.

Most work to date has been done using composites consisting of a symmetrical sequence of lay up. Some low velocity impact work has shown that the sequence of lay up for a symmetrical lay up has a minor effect on the resistance to penetration whereas target thickness and loading rate have a greater significance [11]. The sequence of lay up for symmetrical composites only seems to have a small effect on the impact response of CFRP laminates at much higher velocities as well [8]. However, the effect of the sequence of lay up on asymmetric composite materials on their energy absorption ability and the consequential damage have not been extensively studied. Furthermore, for the study of impact and penetration of CFRP laminates there is a paucity of data on the oblique penetration of these types of materials and, in particular, woven CFRP laminates that are presently used in the aerospace industries. Most impacts from high velocity projectiles will occur with some degree of obliquity and consequently, it is important to understand the effect that obliquity has on a penetrating projectile.

In this study, we examine the response of two thicknesses of woven CFRP to impact and penetration by a fully annealed stainless steel sphere between the velocity regime of $170 \mathrm{~m} / \mathrm{s}$ and $374 \mathrm{~m} / \mathrm{s}$. Both impact at normal incidence and impact at an oblique angle of $45^{\circ}$ are studied. This work is part of a wider study on the dynamic behaviour of woven CFRP laminates. 


\title{
EXPERIMENTAL METHODOLOGY
}

\author{
Materials Used
}

The materials chosen for this study were woven CFRP laminates that were manufactured using the resin transfer moulding method (RTM). These laminates were chosen because they are commonly used in the aerospace industry. Two different thicknesses of CFRP material supplied by Short Brothers plc. were tested: $3 \mathrm{~mm}$ and 6 mm. All individual panels were manufactured with Hexcel G0926 Carbon Fabric with a 5 harness satin weave. The resin used was Hexcel RTM 6 cured for 1 hour 40 minutes at $180{ }^{\circ} \mathrm{C}$ and at a pressure of 100 psi. The $3 \mathrm{~mm}$ thickness CFRP panels comprised of 8 plies in a quasi-isotropic $( \pm 45,0 / 90, \pm 45,0 / 90)_{s}$ lay-up. The 6 -mm thick CFRP panel was made from 16 plies with the lay-up (0/90, $\pm 45, \pm 45,0 / 90, \pm 45, \pm 45,0 / 90,0 / 90, \pm 45$, $0 / 90, \pm 45,0 / 90, \pm 45,0 / 90, \pm 45,0 / 90)$. Separate results are presented for panels that were orientated so that the impact occurred on the $(0 / 90, \pm 45, \pm 45)$ face and the $(0 / 90$, $\pm 45,0 / 90$ ) face. The density of the CFRP material, measured using a Micrometrics AccuPyc 1330 gas pycnometer, was $1.512 \mathrm{~g} / \mathrm{cc} \pm 0.001 \mathrm{~g} / \mathrm{cc}$. The mass fraction of the reinforcement was measured using the acid digestion method according to ASTM D 3171-6, Procedure B. [12] and was found to be $69.7 \pm 1.0 \%$ for the $6 \mathrm{~mm}$ thick composite and $66.4 \pm 0.3 \%$ for the $3 \mathrm{~mm}$ thick samples. 
Impact testing

The projectile used was a fully annealed stainless steel sphere $(\varnothing 11.97 \mathrm{~mm} \pm 0.01$ mm; mass $=7.165 \mathrm{~g} \pm 0.001 \mathrm{~g}$; VHN $=127$ ). The balls (SS304) were fully annealed in air at $1050^{\circ} \mathrm{C}$ to provide equiaxed austenite grains and consequently isotropic behavior. The yield strength of this steel at $21^{\circ} \mathrm{C}$ is $450 \mathrm{MPa}$ with an ultimate tensile strength of 675 MPa [13]. The projectile was fired from ELVIS, a single stage $\varnothing 22-m m$ gas-gun. Target specimens were cut from supplied material into $150 \mathrm{~mm} \times 150 \mathrm{~mm}$ squares using a diamond-wheel cutter and secured into a target holder by clamping at the top and bottom of the specimen. Some $6 \mathrm{~mm}$ thick panels were also clamped at the bottom only in order to evaluate the influence of clamping on the impact properties of the laminates. For the oblique targets, the target was mounted at $45^{\circ}$ from the horizontal (see Figure 1). The projectile was mounted in a sabot that was stripped away before it struck the target.

\section{Figure 1}

The energy transferred to the panel was assessed by measuring the impact velocity and the exit velocity of the projectile to an accuracy of $<1 \%$ using a high speed video camera (Phantom 7) at 18,000 pictures-per-second with an exposure time of $2 \mu \mathrm{s.}$ The energy transferred to the target $\left(E_{t}\right)$ was calculated from

$E_{t}=\frac{1}{2} m_{p}\left(v_{i}^{2}-v_{r}^{2}\right)$ 
where $m_{p}$ is the mass of the projectile, and $v_{i}$ and $v_{r}$ are the impact and residual velocities. Consequently, the percentage change in kinetic energy $\left(\Delta E_{f}\right)$ was calculated using $\Delta E_{f}=\frac{E_{t}}{E_{i}} \times 100$

where $E_{i}$ is the kinetic energy of the projectile prior to impact.

Parallax was taken into account by knowing the distances from the lens to the axis of penetration and from the axis of penetration to fiduciary markers. Debris that was ejected from the targets was recovered using multiple layers of cotton cloth.

The extent of damage in the perforated composites was assessed by doing C-scans using a glass reflector technique with a $5 \mathrm{MHz}, 50 \mathrm{~mm}$ crystal focus transducer. The scans were carried out by Midas NDT Systems Ltd. using a $1 \mathrm{~mm}$ grid and a scan speed of 100 $\mathrm{mm} / \mathrm{s}$.

\section{RESULTS AND DISCUSSION}

\section{Change in energy}

The change in the kinetic energy (KE) for the $3 \mathrm{~mm}$ and $6 \mathrm{~mm}$ targets is shown below in Figure 2. A third order polynomial is fitted to all data except the $3 \mathrm{~mm}$ normal incidence results. In only one case the projectile did not perforate but rebounded from the target. This occurred for the $6 \mathrm{~mm}$ oblique shot with an impact velocity of $194 \mathrm{~m} / \mathrm{s}$ (135 J) and is 
highlighted by the grey shaded symbol. It rebounded from the target with a kinetic energy of $1.8 \mathrm{~J}$ and is included in this work for completeness.

Figure 2

There are four things to note here.

Firstly, two projectiles were shot at the $6 \mathrm{~mm}$ asymmetric panels from a different aspect to test the effect of the lay-up of the target on its ballistic performance. From these results (the grey diamonds in Figure 2) the effect of the lay-up on the ballistic performance is negligible. Tanabe et al [9] have shown that small differences in ballistic performance are possible if carbon fibres of different properties are used in the throughthickness of the sample. They also noted that there was little difference in the absorbed energy when cross ply laminates were compared to woven laminates. This may suggest that the structure of the CFRP is of secondary importance when compared to the fibre properties. However, Hammond et al [8] showed that thin laminates of different cross-ply lay-ups did exhibit a difference in energy absorption. However, they do note that the measured difference was small and was well within their experimental error.

Secondly, the percentage of kinetic energy absorbed reduces with increasing kinetic energy of the projectile. This has been observed by other researchers studying these types of materials [9] and is due, in part, to the change in penetration mechanism of the projectile from that of causing petalling where the fibre tows are loaded in tension, to causing compression / shear failure in the target. For the normal incidence targets it was evident that at lower velocities the failure is dominated by petalling (see Figure 3) whereas at higher velocities the failure of the target is dominated by plug formation. This 
behavior has been shown by a number of previous researchers $[7,9,14]$ and will be discussed in detail in the next section.

Figure 3

Thirdly, the oblique targets appear to perform better than targets impacted at normal incidence. This is a common feature when projectiles are fired at metallic targets. However, this is merely an effect of the increase of material thickness offered to the projectile as the angle of obliquity is increased. In Figure 4, we have plotted the KE transferred to the target normalized by the thickness of material offered to the projectile with impact energy. For the oblique targets the linear thickness offered to the projectile is calculated by $t / \cos \theta$ where $t$ is the thickness of the CFRP specimen and $\theta$ is the angle of obliquity, $45^{\circ}$ in this case. For both thicknesses of target at a given impact energy, the kinetic energy transferred per effective linear thickness offered to the projectile is consistent regardless of whether the penetration occurs at normal incidence or oblique incidence. Consequently, over the impact velocity range of interest, for both targets, the oblique angle does not have any further effect on the resistance to penetration other than offering more material to penetrate. There is one further thing to note from this Figure: the $6 \mathrm{~mm}$ CFRP panels provide better resistance to penetration per unit thickness of material than the $3 \mathrm{~mm}$ panels at the lower impact energies. When the velocity of impact is increased the difference between the two panels effectively vanishes. This may well be due to the importance of petalling in the $6 \mathrm{~mm}$ target and the resulting energy absorption due to delamination. For thicker targets more layers are bent in the petalling process and consequently it is harder for the projectile to push the petals away from its path. This 
leads to higher energy absorption. As petalling becomes less dominant the "advantage” for the thicker target reduces.

\section{Figure 4}

Finally, three firings into the $6 \mathrm{~mm}$ CFRP laminate were conducted using a different jig arrangement that clamped the target along one edge only as opposed to two edges. This did not affect the results however we have separated these data points from those of the fully-clamped results for clarity. This observation is in keeping with Cantwell and Morton [7] who have shown that high velocity projectiles induce a localised response in the composite material. Any flexing of the top of the sample afterwards due to being unrestrained at one edge occurred at a very low linear velocity $(\sim 3-5 \mathrm{~m} / \mathrm{s})$.

\section{Perforation mechanisms}

Different perforation mechanisms were observed over the velocity range of interest: perforation dominated by petalling and perforation dominated by plug formation.

Figure 5 shows the impact, penetration and perforation of a $6 \mathrm{~mm}$ target by a steel sphere that has an impact energy of $125 \mathrm{~J}(187 \mathrm{~m} / \mathrm{s})$. Here we see that failure is dominated by petalling of the rear surface plies (see Figure 3). During the initial stages of penetration, bulging of the rear surface is evident. Eventually tensile failure of the rear plies ensues and the projectile is able to perforate. The petals that are formed are pushed 
apart by the projectile and eventually relax, partially closing up the penetration cavity. It was evident that relatively few fragments were formed as the projectile exits the target.

Figure 6 shows the penetration of a $6 \mathrm{~mm}$ CFRP laminate by a projectile that has an impact energy of $450 \mathrm{~J}$ (354 m/s). On impact a significant amount of delamination and fibre breakage occurs. A plug is pushed ahead of the projectile and maintains a similar velocity to the projectile as it moves away from the rear of the target.

\section{Figure 5}

\section{Figure 6}

\section{Figure 7}

Figure 7 shows evidence contrasting the damage mechanisms for the $6 \mathrm{~mm}$ targets shown in the high speed video images in Figures 5 and 6. In Figure 7(a), the projectile has perforated the target; the penetration channel is not visible due to the relaxation of the plies. In Figure 7(b) the penetration has been dominated by plugging and consequently the penetration channel is visible.

Other researchers have also observed plug formation during the penetration of CFRP materials. Li and Sun [15] noted plug formation in thin CFRP laminates that had been struck by a blunt-ended projectile at relatively low velocities ( $<100 \mathrm{~m} / \mathrm{s})$. Cantwell and Morton [16] have previously shown that during the perforation of a thin CFRP material, a frustum-shaped fracture zone is formed. This observation is consistent with the conically shaped plugs that we soft-captured. A recovered plug is shown below in Figure 8 . The white arrows indicate examples of relatively sharp fracture surfaces at the 
top of the plug whereas towards the bottom of the plug the fractured tows show jagged edges consistent with tensile failure resulting in fibre pull-out. An example is shown in the white oval. Simultaneous shear failure of the front tows with tensile failure of the rear layers is not possible unless dishing is occurring in the sample. That is, as the projectile penetrates the initial plies are subjected to a shearing mechanism whilst the rear part of the laminate is deforming in a dished fashion. There is evidence of this from the high speed photography (see Figure 9). Eventually, the state of tension in the dished portion of the sample leads to tensile failure of the tows. An initial shear failure close to the impact surface followed by a tensile failure of the fibres towards the rear of the sample has also been observed by Cantwell and Morton [16] with thick (8 mm) laminates struck with high velocity spheres. However, they did not report the recovery of a plug in this instance. Given that the recovered plugs in this trial were nominally $5 \mathrm{~mm}$ thick for the 6 mm CFRP laminates and the observed dishing in the high speed video, we believe that the combined shear / tensile failure is a reasonable assessment of the penetration mechanism in these woven laminates.

Figure 8

Figure 9

For the 6 mm CFRP panels, a plug was also formed when the p.ojectile impacted the target with an energy of $359 \mathrm{~J}$. However at $211 \mathrm{~J}$, it was unclear from the high speed video as to whether plugging was occurring; no penetration channel was evident when the target was viewed from the impact face. Consequently, it is likely that the penetration mechanism undergoes a transition from a mechanism dominated by petalling at $125 \mathrm{~J}$ to 
one that is dominated by plug formation at $359 \mathrm{~J}$. Similar behaviour occurred with the 3 mm CFRP targets. At lower impact velocities, post mortem analysis revealed that petalling had occurred for the energies of impact of $103 \mathrm{~J}$ and $155 \mathrm{~J}$; in these cases, no clear penetration channel was visible. When the energy of impact was increased to $303 \mathrm{~J}$, a clear penetration channel was evident and thin plug was recovered.

The effect of obliquity on perforation

For the $3 \mathrm{~mm}$ and $6 \mathrm{~mm}$ oblique targets it was unclear from the high speed video as to whether plugging was occurring. This was due to the fact that during the early stages of the projectile exiting the rear of the target, it was obscured by CFRP debris. However, it is clear that during penetration, a large amount of debris is ejected in a general direction perpendicular to the rear of the target (see the white arrows in Figure 10). The projectile's course was altered very little by the oblique CFRP panel.

\section{Figure 10}

With the $3 \mathrm{~mm}$ oblique targets there was no visibie change to the penetration channel within the velocity of interest. However, for the $6 \mathrm{~mm}$ target, it was apparent that perforation did not occur at the lowest velocity of impact tested $(194 \mathrm{~m} / \mathrm{s}=135 \mathrm{~J})$. However, increasing the impact velocity to $226 \mathrm{~m} / \mathrm{s}$ ( $183 \mathrm{~J}$ ) resulted in perforation. Figure 11 shows the initial stages of penetration for a $3 \mathrm{~mm}$ and $6 \mathrm{~mm}$ CFRP laminate being penetrated by the steel projectile. Impact energies are $129 \mathrm{~J}(190 \mathrm{~m} / \mathrm{s})$ and $135 \mathrm{~J}$ (194 m/s) respectively. During the initial stages, bulging occurs in a direction 
perpendicular to the rear face of the target until the rear face fractures due to the penetrating projectile. Consequently, what appear to be petals are broken off and pushed ahead of the projectile. For the $6 \mathrm{~mm}$ case, the projectile did not perforate. Nevertheless, the high-speed video revealed that the initial stages of penetration, at least, appear to occur in a similar fashion. The rear face of the $6 \mathrm{~mm}$ target was petalled (see Figure 12(e)) with tears appearing in a Latin-cross-like fashion whereas with the $3 \mathrm{~mm}$ thick sample (Figure 12(a)) a hole was left. Given that we observed the bulging in the high speed video and that the penetration mechanisms initially appear similar to that of the 6 mm case, we conclude that the petals have been formed and broken off in this instance.

\section{Figure 11}

\section{Figure 12}

For all the targets that were perforated, there did not appear to be a transition in penetration mechanism from petalling to plugging. No visible plug was seen on the high speed video nor recovered. Unlike the targets that were orientated at normal incidence, the $3 \mathrm{~mm}$ targets exhibited a very clear penetration channel visible throughout the velocity range of interest (see Figure 12(a-d)). For the $6 \mathrm{~mm}$ oblique samples, three targets had clear penetration channels for impact energies of $259 \mathrm{~J}, 360 \mathrm{~J}$ and $479 \mathrm{~J}$ (Figure 12(g-i)). Only one target that was perforated (at $183 \mathrm{~J}$ ) did not reveal a clear penetration channel indicating that the petals that were formed relaxed after projectile perforation (Figure 12f). 
The fracture surface of the $6 \mathrm{~mm}$ oblique CFRP impacted at $479 \mathrm{~J}(366 \mathrm{~m} / \mathrm{s})$ is exhibited in Figure 13 where the upper section of the panel is shown on the left and the lower section is on the right. For all the oblique panels where perforation occurred, the lower section showed a clean fracture of the different layers whereas on the top section, a brush-like surface was observed (see also Figure 12). Due to the obliquity of the composite panels, the fracture of the material by the projectile was asymmetrical: shear failure of the laminae and fibres appeared to dominate on the lower side, while tensile forces appear to dominate on the upper section resulting in greater delamination in this area.

For the $3 \mathrm{~mm}$ oblique targets, an open hole similar to the one in the $6 \mathrm{~mm}$ oblique targets was created in all the panels with similar fracture characteristics in the upper and lower sections (see Figure 12).

\section{Figure 13}

\section{Damage assessment}

To elucidate the degree of damage further, sections of the perforated CFRP panel were mounted in polyester mounting resin, ground, polished and then viewed under an optical microscope. Delamination and matrix cracks were seen between the different laminates but also between different fibre tows: between the $+45^{\circ}$ and the $-45^{\circ}$ tows in the $\pm 45^{\circ}$ laminates, and between the $0^{\circ}$ and $90^{\circ}$ tows in the $0 / 90$ laminates. Cracks were also observed to have propagated across and along fibre tows (see Figure 14). 


\section{Figure 14}

The targets were C-scanned to examine the extent of the damage to the panels. An image analyzer program was used to measure the damage zone when the signal attenuation was greater than $5 \mathrm{~dB}$. For the targets impacted at a velocity close to the minimum required to perforate the target, the cavity had partially closed therefore giving a misleading representation of the size of the penetration channel. Consequently, the results presented in Figure 15 include the hole size and represent the total area of damage. It was noted that in the majority of the normal incidence impact cases the area of delamination was mostly circular. However, for the obliquely impacted samples, the Cscans revealed that the delamination was greater at the top of the penetration channel. Figure 15 summarises the results.

Figure 15

Despite the fact that we must be cautious in drawing too many conclusions from these results due to the fact that these scans provide a two-dimensional view of damage instead of a full three-dimensional picture, there are a number of observations to note here. Firstly, for the $6 \mathrm{~mm}$ target that has been struck at normal incidence, the damaged area reduces when the impact energy is increased from $125 \mathrm{~J}$ to $211 \mathrm{~J}$. Similar behaviour has been reported by Tanabe et al [9] and Lopez-Puente et al [14] for relatively thin laminates. For these relatively thick $6 \mathrm{~mm}$ laminates, the drop-off in the area of delamination can be explained in terms of the transition from petalling type failure to that of penetration dominated by plugging behaviour. However, as we have previously noted, no intact plug was recovered at an impact energy of $211 \mathrm{~J}$. To elucidate this behaviour 
further, two targets were sectioned, mounted in polyester resin, ground and polished to interrogate the level of delamination through the thickness using an optical microscope. The targets chosen represented cases where purely petalling type failure had occurred and where a plug formation was clearly evident from the high-speed video. To visualize the through-depth damage, the degree of cracking was traced and is shown schematically in Figure 16 for impact energies $125 \mathrm{~J}$ and $333 \mathrm{~J}$. Interestingly we see that for the panel that has been perforated by a relatively low velocity projectile, damage is more extensive towards the rear of the target and cracking extends much further than is observed in a target that has been perforated by a higher velocity projectile. This is consistent with extensive dishing that occurs prior to tensile failure of the petals. Consequently, the reduction of damage observed by the $\mathrm{C}$-scans is indicative of a change in penetration mechanisms as the projectile perforates the target. In both examples it is clear that the level of damage increases through the thickness.

Secondly, the damage area in the $6 \mathrm{~mm}$ oblique targets also decreases with increasing impact energy however suffers greater delamination than the $6 \mathrm{~mm}$ normal incidence results. We believe that the greater level delamination at oblique angles is due to the geometry of penetration. In the early stages of penetration, deformation occurred in a direction perpendicular to the rear of the target plate as discussed previously (see Figure 11 ) and at the lower impact energies resulted in petalling (see Figure 12 (e)). Due to the effective linear thickness of penetrated material being higher in the oblique targets than the normal targets and given the perpendicular bulging of the target, a greater volume of material was damaged by the projectile. This resulted in a greater measured area of delamination. 
Thirdly, a similar level of damage is observed with the C-scans and from the through-thickness analysis for the $6 \mathrm{~mm}$ thick asymmetric targets impacted at normal incidence regardless of the direction of impact. Consequently, we conclude that for this CFRP laminate, the sequence of lay-up has no effect on the penetration mechanism.

Fourth, the $3 \mathrm{~mm}$ laminates appear to demonstrate similar amounts of delamination regardless of whether the impact was at normal incidence or at an oblique angle. This is probably due to the fact that the level of damage has already plateaued before the minimum impact velocity in these experimental trials. Indeed, Tanabe et al. [10] have shown that with their CFRP laminates the drop-off in area damage occurs at an impact energy of $20 \mathrm{~J}$ for 4 and $5 \mathrm{~mm}$ diameters spheres impacting $2 \mathrm{~mm}$ thick CFRP panels.

Finally, as the impact energy is increased, the area of damage appears to approach an asymptotic level for the thicker targets tested. Whereas, for the thinner targets, the amount of damage appeared to remain constant regardless of impact energy. Given that the percentage change in kinetic energy for all composites reached a plateau in the range of impact energies tested (see Figure 2) this may suggest that the main energy absorbing mechanism at the higher impact energies is not damage related. This is because at the higher impact energies the percentage of energy absorbed increases with impact energy whilst the level of damage remains constant. One probable cause of the observed effect is that more energy is being transferred to the debris in the form of kinetic energy. However, further work at higher impact velocities is required to elucidate this matter. 


\section{CONCLUSIONS}

A series of impact experiments have been conducted on $3 \mathrm{~mm}$ and $6 \mathrm{~mm}$ thick woven carbon-fibre laminates at normal and oblique impact angles and the failure mechanisms, degree of damage, and energy transferred to the plate have been discussed. At lower impact velocities it was noted that with the $6 \mathrm{~mm}$ panel, the penetration mechanism was dominated by the tensile failure of the rear weave and the consequent petalling. As the velocity of impact was increased from $170 \mathrm{~m} / \mathrm{s}$, a conical mass of laminate was ejected. Despite the energy transferred to the plate increasing with impact energy, the degree of delamination for the $6 \mathrm{~mm}$ targets, as measured by C-scan and by microscope observations, decreased and we conclude that this was due to the change in penetration mechanism from that of petalling to plugging. Eventually, the degree of delamination appeared to approach an asymptotic level. For the $3 \mathrm{~mm}$ targets, the degree of delamination remained constant regardless of impact energy.

A similar level of energy absorption and damage was observed for the $6 \mathrm{~mm}$ thick asymmetric targets impacted at normal incidence regardless of the direction of impact. Consequently, we conclude that for this CFRP laminate, the sequence of lay-up has no effect on the panel's impact properties and on the penetration mechanism.

For the targets that have been impacted at an oblique angle more of the kinetic energy is transferred from the projectile when compared to the same thickness of target that has been subjected to a normal incidence impact. However, we have shown that this is merely due to a geometrical effect. We have also shown that thicker panels appear to 
behave more efficiently by absorbing more kinetic energy per effective linear thickness at the lower impact energies where petalling is a dominant factor in the penetration. This advantage appears to vanish as the impact energy is increased.

\section{ACKNOWLEDGEMENTS}

The authors would like to thank Mr Keith Campbell of Short Brothers plc, Belfast, UK for supplying the CFRP panels. We also would like to thank Drs John Rock and Jonathan Painter for their valuable time on the Scanning Electron Microscopes. We gratefully acknowledge the UK MoD and the EPSRC who funded this work under GR/S33994/01. We also acknowledge DOSG (UK) who funded the development of ELVIS - the gun used in this experimental programme.

\section{REFERENCES}

1. Cantwell WJ, Morton J. The impact resistance of composite materials - a review. Composites 1991;22(5):347-362.

2. Richardson MOW, Wisheart MJ. Review of low-velocity impact properties of composite materials. Composites Part A: Applied Science and Manufacturing 1996;27(12):1123-1131.

3. Morton J, Godwin EW. Impact response of tough carbon fibre composites. Comp Struct 1989;13:1-19. 
4. Cantwell WJ, Curtis PT, Morton J. An assessment of the impact performance of CFRP reinforced with high-strain carbon fibres. Composites Science and Technology 1986; 25(2):133-148.

5. Curtis PT, Bishop SM. An assessment of the potential of woven carbon fibrereinforced plastics for high performance applications. Composites 1984;15(4):259-265.

6. Robinson P, Davies GAO, Impactor mass and specimen geometry effects in low velocity impact of laminated composites. Int. J Impact Engng 1992;12(2):189-207.

7. Cantwell WJ and Morton J. Comparison of the low and high velocity impact response of CFRP. Composites 1989;20(6): 545-551.

8. Hammond RI, Proud, WG, Goldrein HT and Field, JE. High-resolution optical study of the impact of carbon-fibre reinforced polymers with different lay-ups. Int J impact Engng 2004;30:69-86.

9. Tanabe Y, Aoki M, Fujii K, Kasano H, Yasuda E. Fracture behavior of CFRPs impacted by relatively high-velocity steel sphere. Int J Impact Engng 2003;28:627-642.

10. Tanabe Y, Aoki M. Stress and strain measurements in carbon-related materials impacted by high-velocity steel spheres. Int J Impact Engng 2003;28:1045-1059.

11. Nemes JA, Eskandari H, Rakitch L. Effect of laminate parameters on penetration of graphite/epoxy composites. Int J Impact Engng 1998;21:97-112.

12. ASTM Standard D 3171-06. Standard Test Methods for Constituent Content of Composite Materials. ASTM International, 2006.

13. Cryogenic materials data handbook, Volume 1, Sections A-C, Air Force Materials Laboratory, Air Force Command, Wright-Patterson Air Force Base, Ohio, AFMLTDR-64-280, 1970. 
14. López-Puente, Zaera R, Navarro C. The effect of low temperatures on the intermediate and high velocity impact response of CFRPs. Composites Part B: Engineering 2002;33(8):559-566.

15. Lee S-WR, Sun CT. Dynamic penetration of graphite/epoxy laminates impacted by a blunt-ended projectile. Composite Science and Technology 1993;49:369-380.

16. Cantwell WJ and Morton J. Impact perforation of carbon fibre reinforced plastics. Composite Science and Technology 1990;38:119-141. 


\section{LIST OF FIGURE CAPTIONS}

Figure 1: The normal and oblique target holders.

Figure 2: Percentage change in KE due to the perforation of normal and oblique targets of different thicknesses.

Figure 3: The resulting petals due to the perforation of the target by a projectile with an impact velocity of $187 \mathrm{~m} / \mathrm{s}(125 \mathrm{~J})$.

Figure 4: Evaluation of the effective linear thickness offered to the projectile during normal and oblique penetration.

Figure 5: Penetration of a 6 mm CFRP laminate panel; impact energy = $125 \mathrm{~J}(187 \mathrm{~m} / \mathrm{s})$. The much lower impact velocity results in no petals being formed. Filmed at 18,000 frames-per-second with an exposure of $2 \mu$ s per frame.

Figure 6: Penetration of a 6 mm CFRP laminate panel showing the formation of a plug; impact energy $=450 \mathrm{~J}(354 \mathrm{~m} / \mathrm{s})$. Filmed at 18,000 frames-per-second with an exposure of $2 \mu$ ser frame.

Figure 7: Rear face of $6 \mathrm{~mm}$ targets that have been struck by a steel sphere at (a) $125 \mathrm{~J}$ (187 m/s) and (b) $450 \mathrm{~J}(354 \mathrm{~m} / \mathrm{s})$.

Figure 8: Recovered plug that was ejected due to the impact of a $6 \mathrm{~mm}$ CFRP at normal incidence at a velocity of $354 \mathrm{~m} / \mathrm{s}$ (450 J).

Figure 9: Dishing of the CFRP prior to the formation of a plug. The impact velocity for this example is $305 \mathrm{~m} / \mathrm{s}$ (333 J).

Figure 10: Oblique penetration of a $6 \mathrm{~mm}$ thick CFRP laminate impacted at $479 \mathrm{~J}$ (366 $\mathrm{m} / \mathrm{s})$. 
Figure 11: Initial stages of penetration for the $3 \mathrm{~mm}$ CFRP target (upper two images) and the $6 \mathrm{~mm}$ CFRP target (lower two images). Time in-between frames $=55 \mu \mathrm{s}$.

Figure 12: Rear faces of oblique targets; increasing impact energy from left to right. Target thicknesses are $3 \mathrm{~mm}$ (a) to (d) and $6 \mathrm{~mm}$ (e) to (i).

Figure 13: Cross-sections of $6 \mathrm{~mm}$ CFRP impacted at $479 \mathrm{~J}(366 \mathrm{~m} / \mathrm{s})$ and $45^{\circ}$. Figure 14: Micrograph of an area of damage close to the periphery of the hole for $6 \mathrm{~mm}$ CFRP sample perforated at $333 \mathrm{~J}(305 \mathrm{~m} / \mathrm{s})$ at normal incidence. The highlighted areas indicate crack propagation that is seen along and across the $90^{\circ}$ tows.

Figure 15: Damage area measured by C-scan for each of the impacted targets.

Figure 16: Traced detail of damage from targets that have been subjected to petalling (left) and plugging (right). 


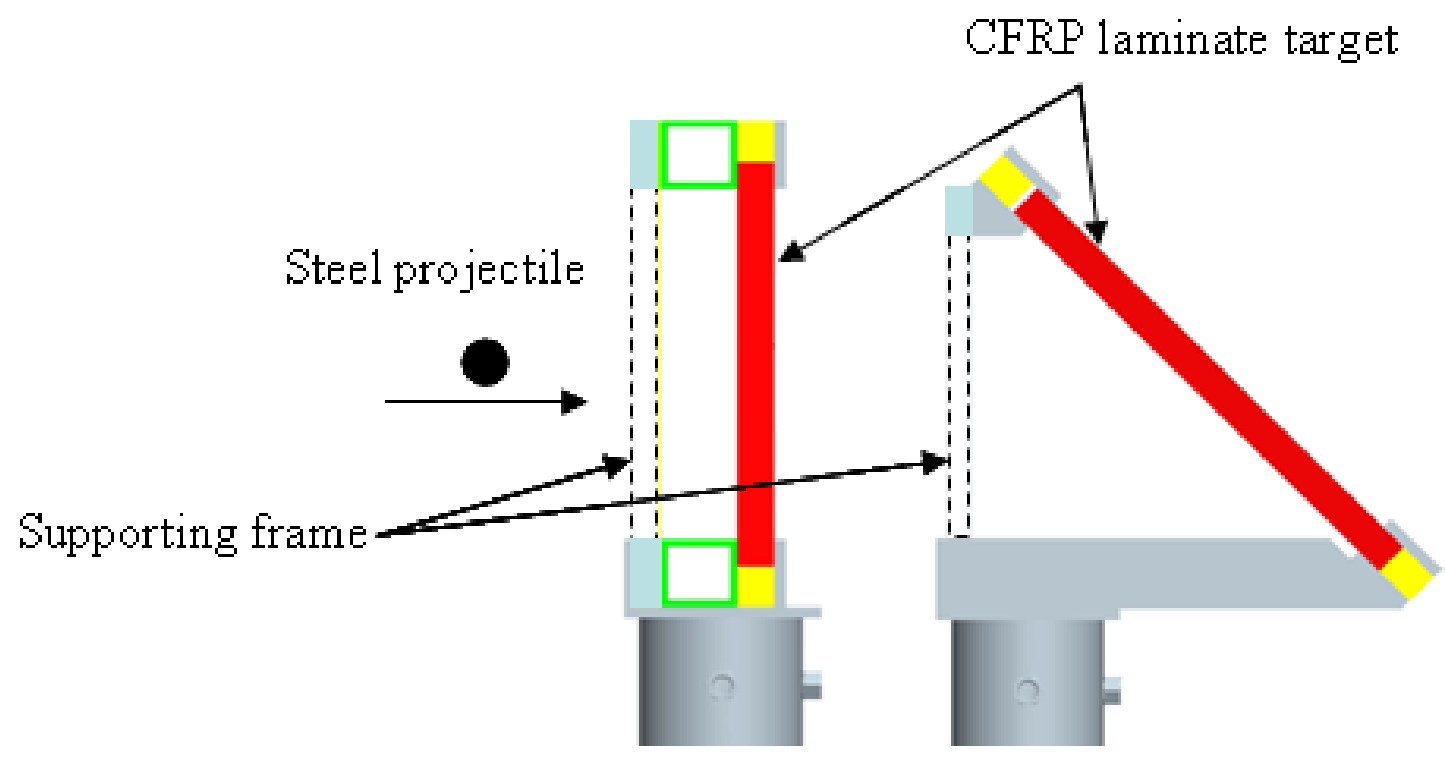

Figure 1 


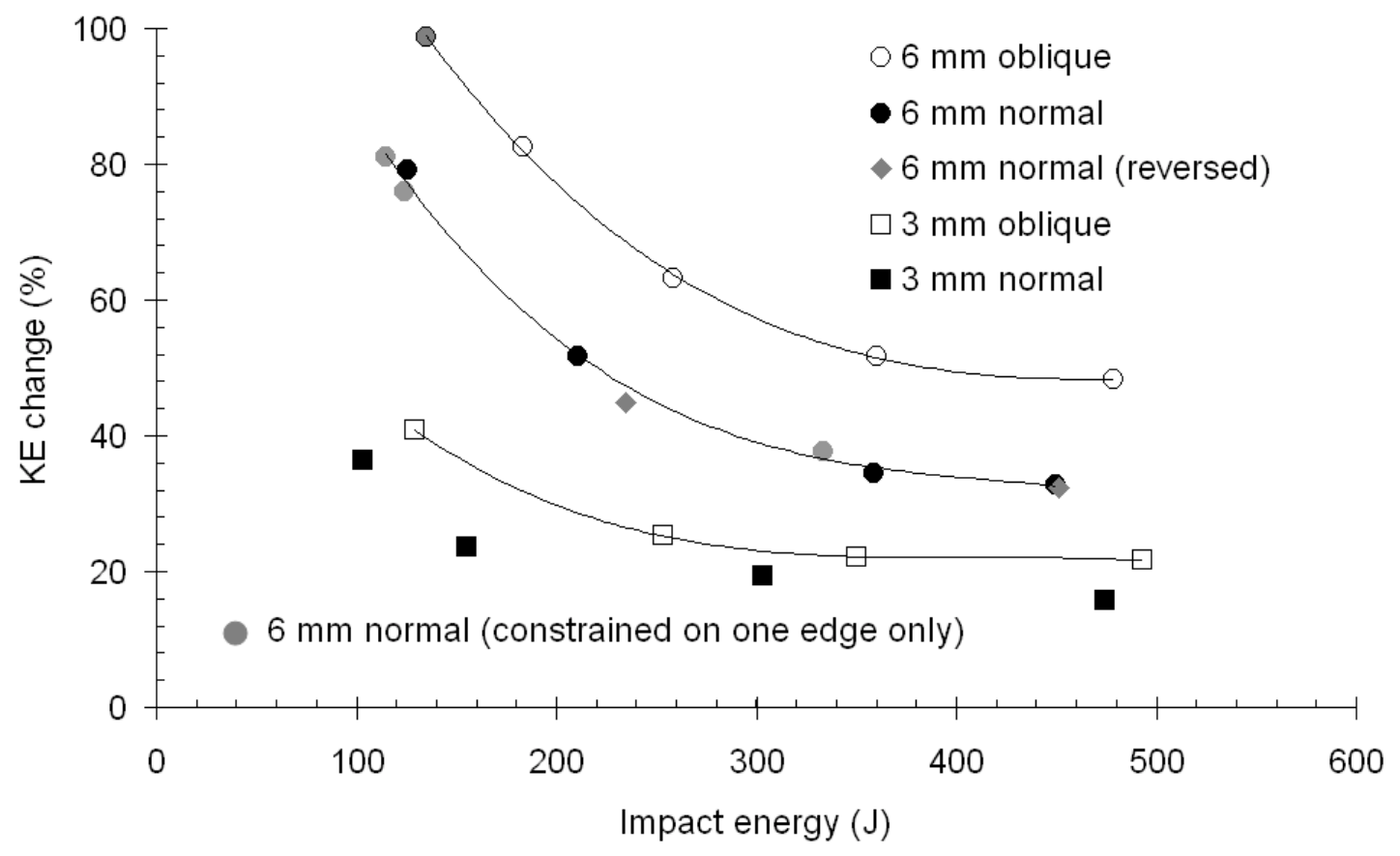

Figure 2 


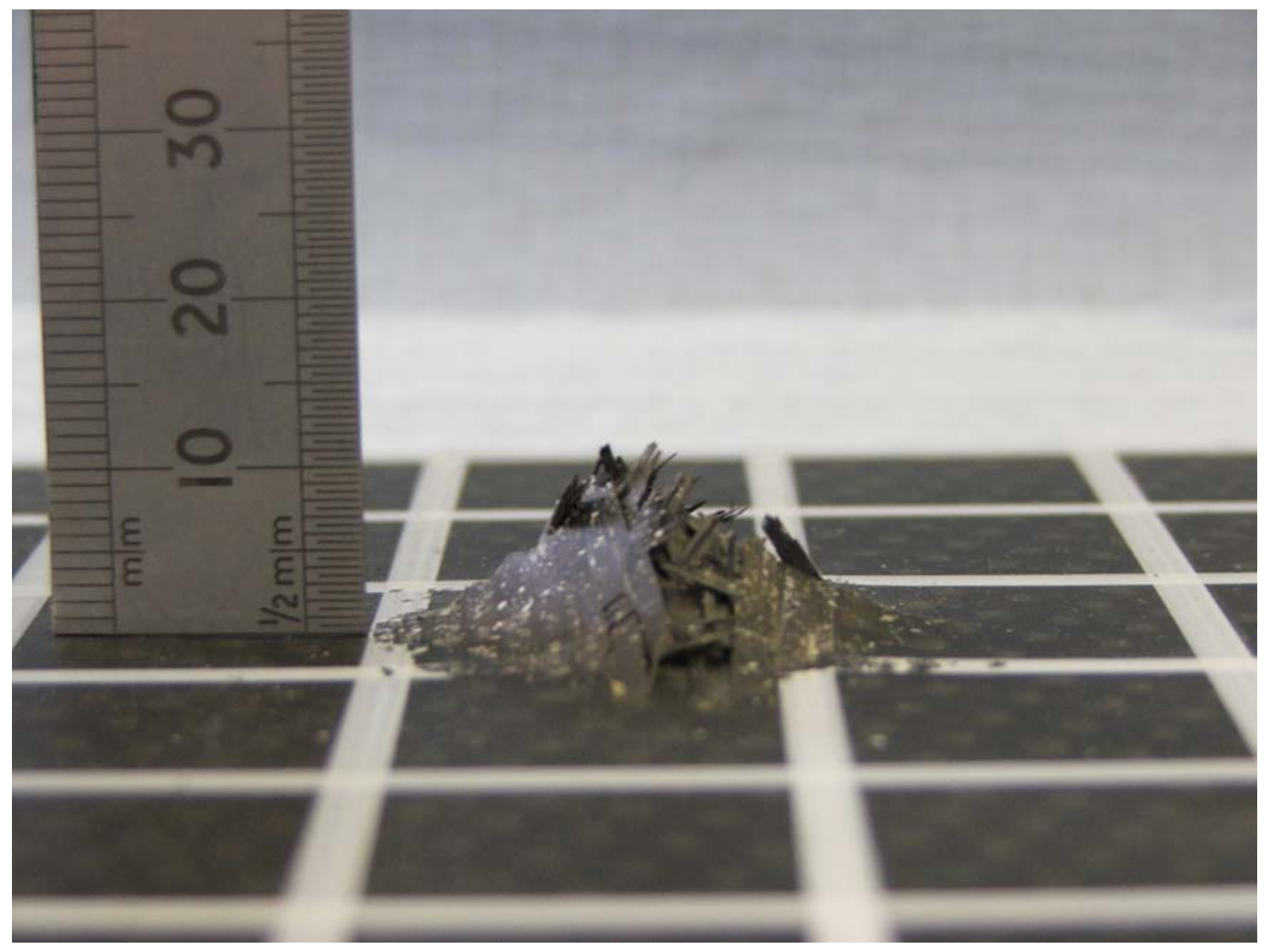

Figure 3 


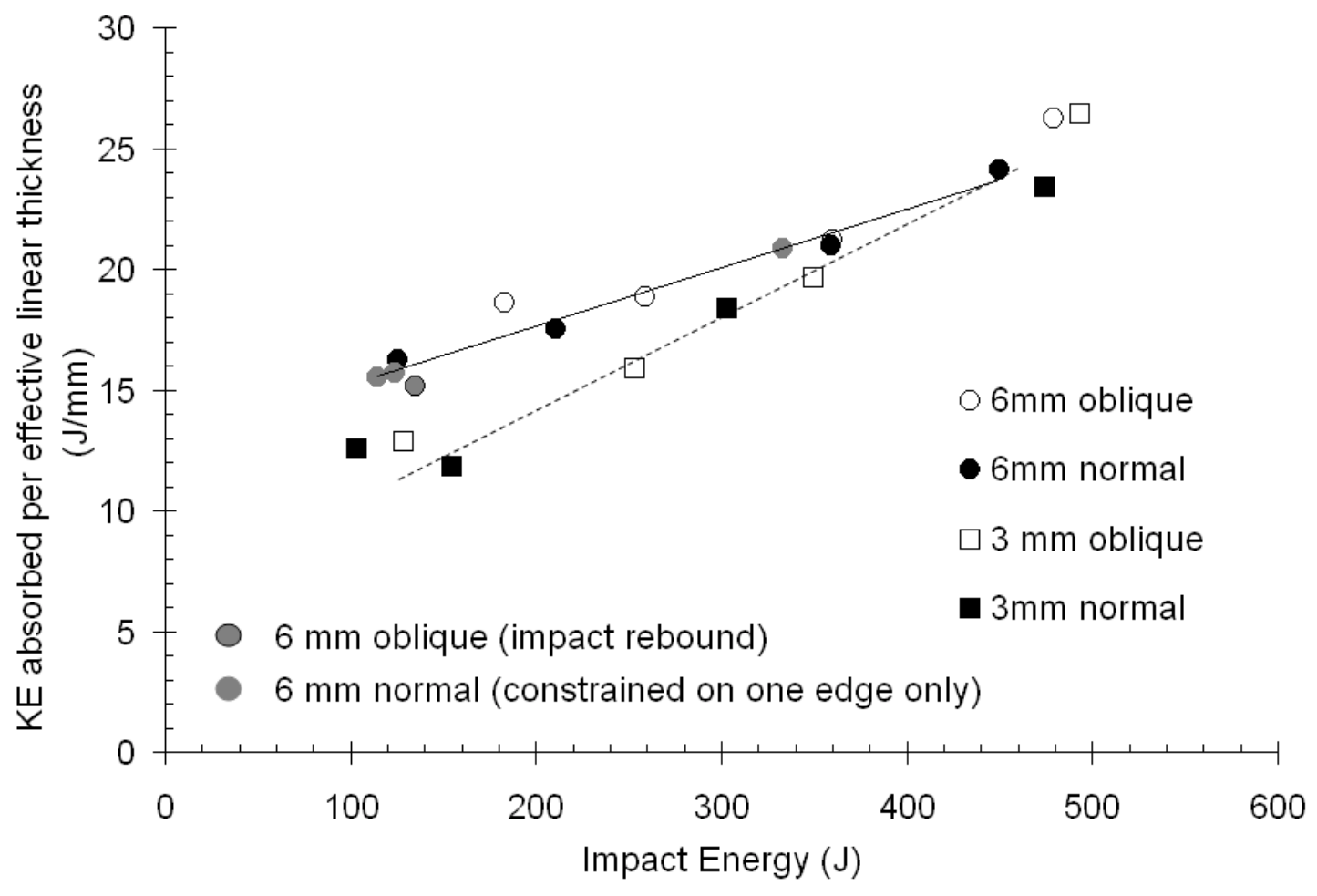

Figure 4 


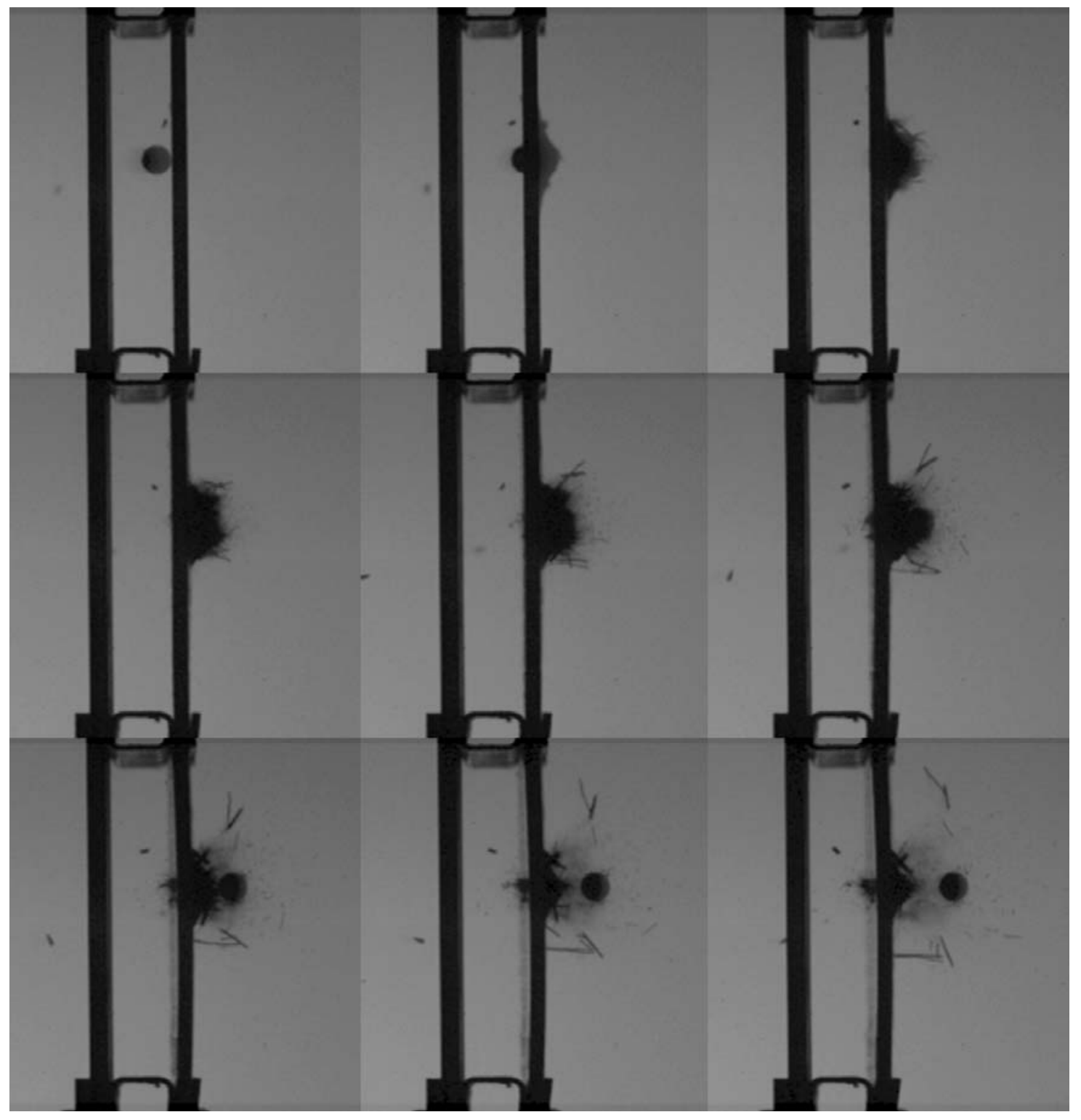

Figure 5 


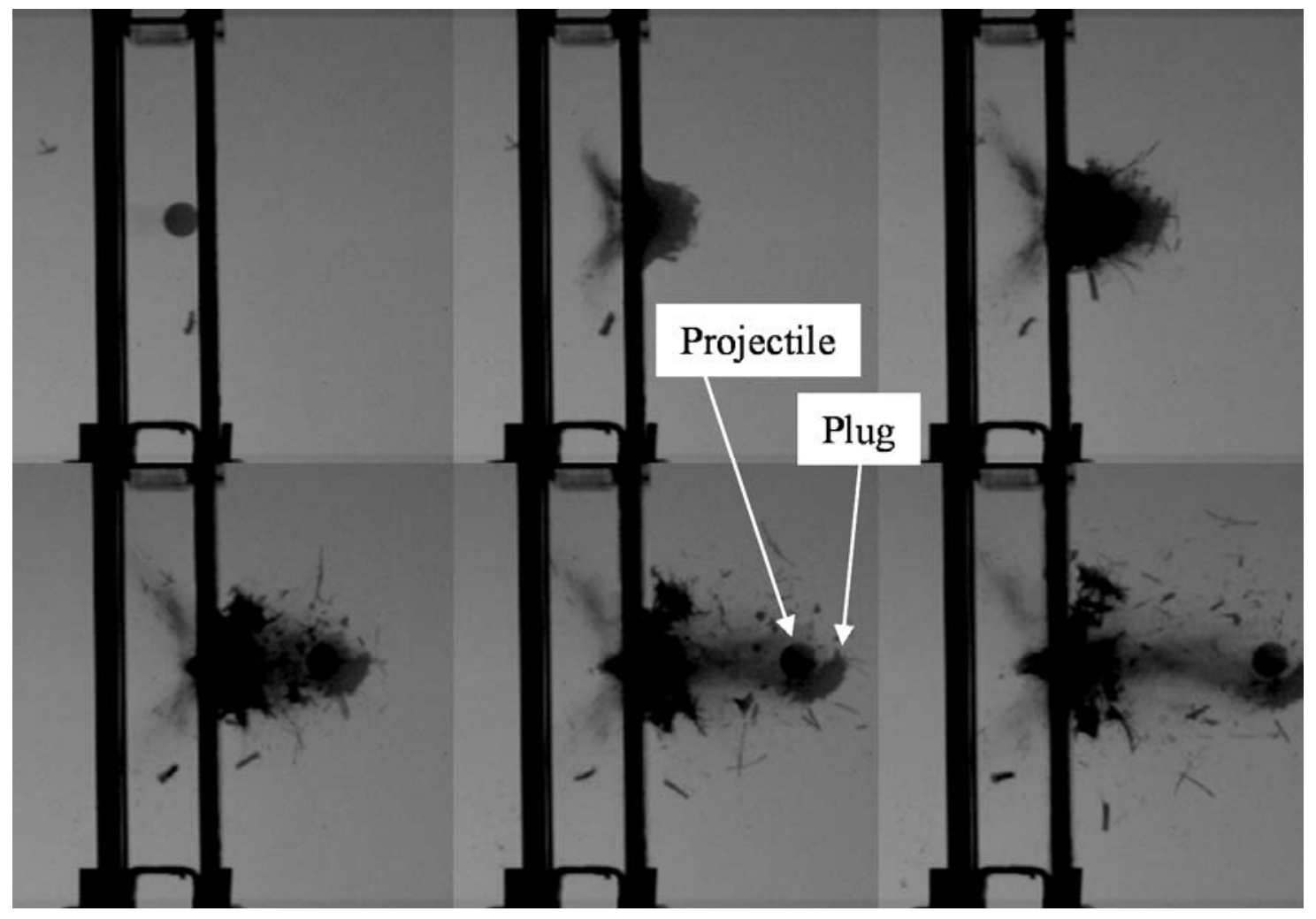

Figure 6 

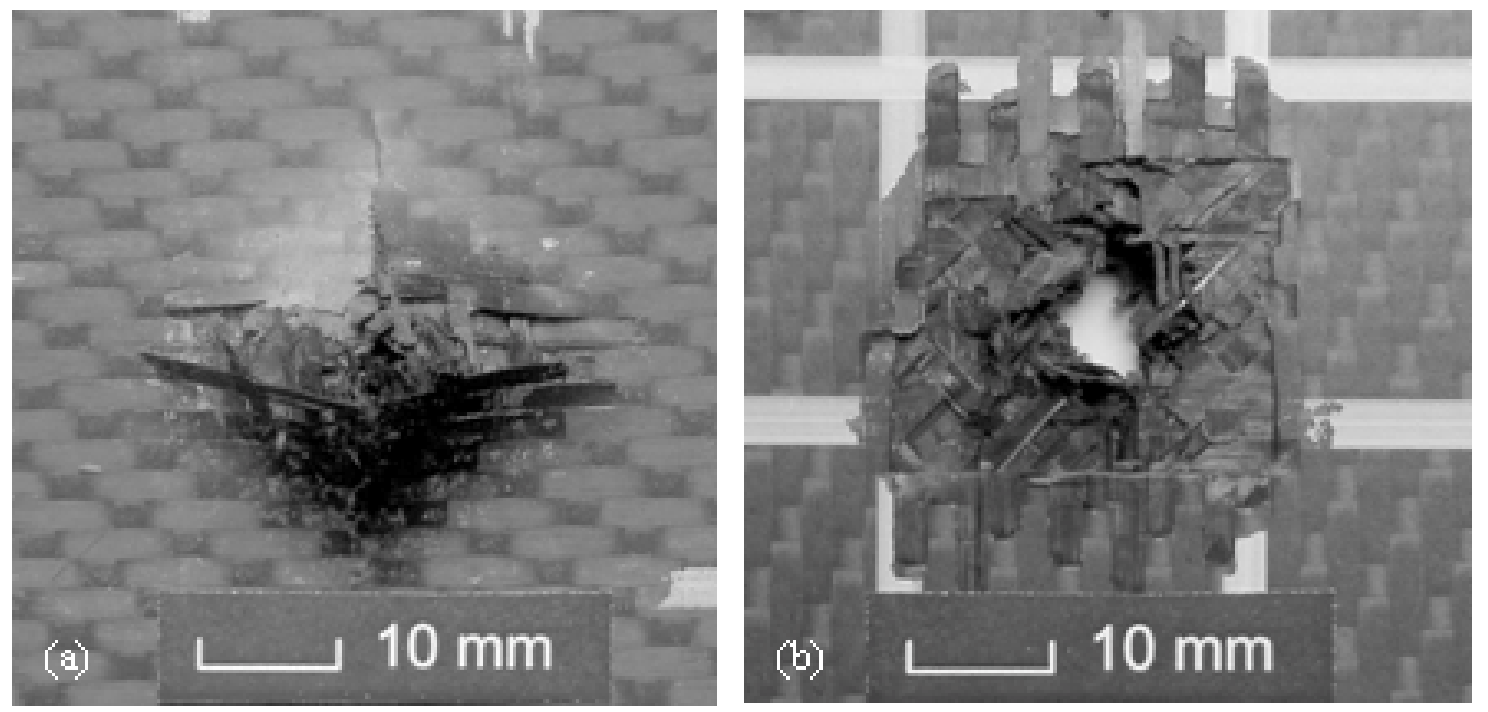

Figure 7 


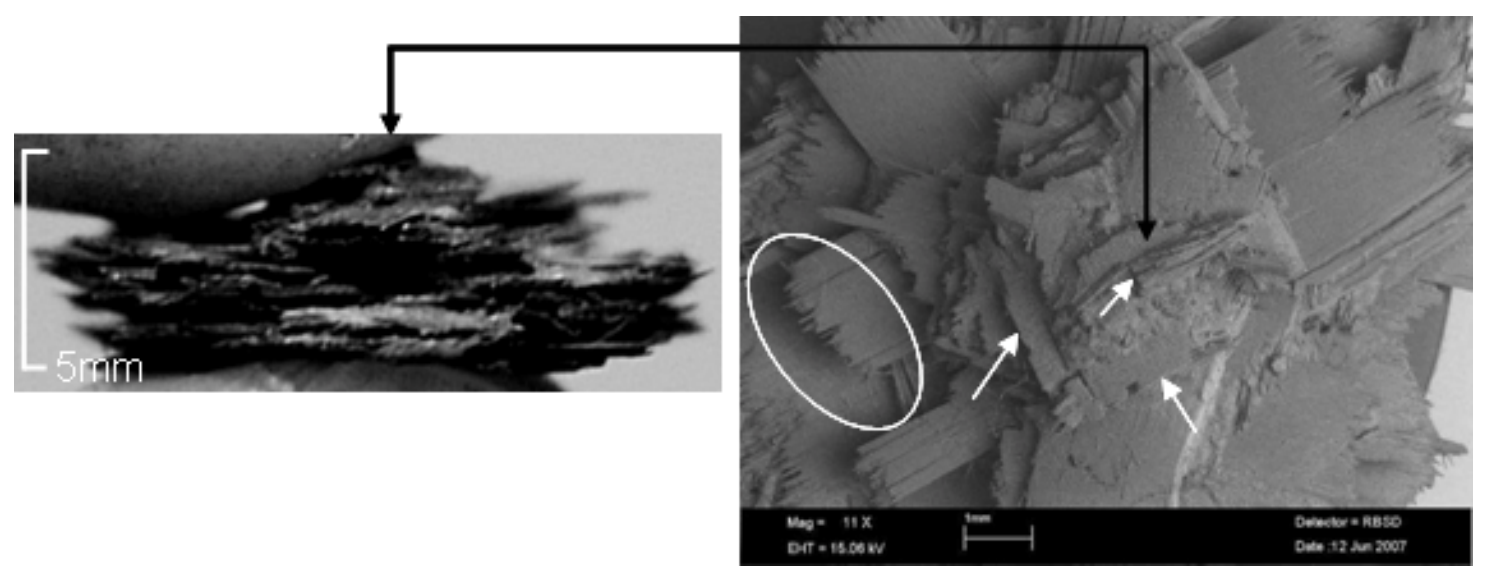

Figure 8 


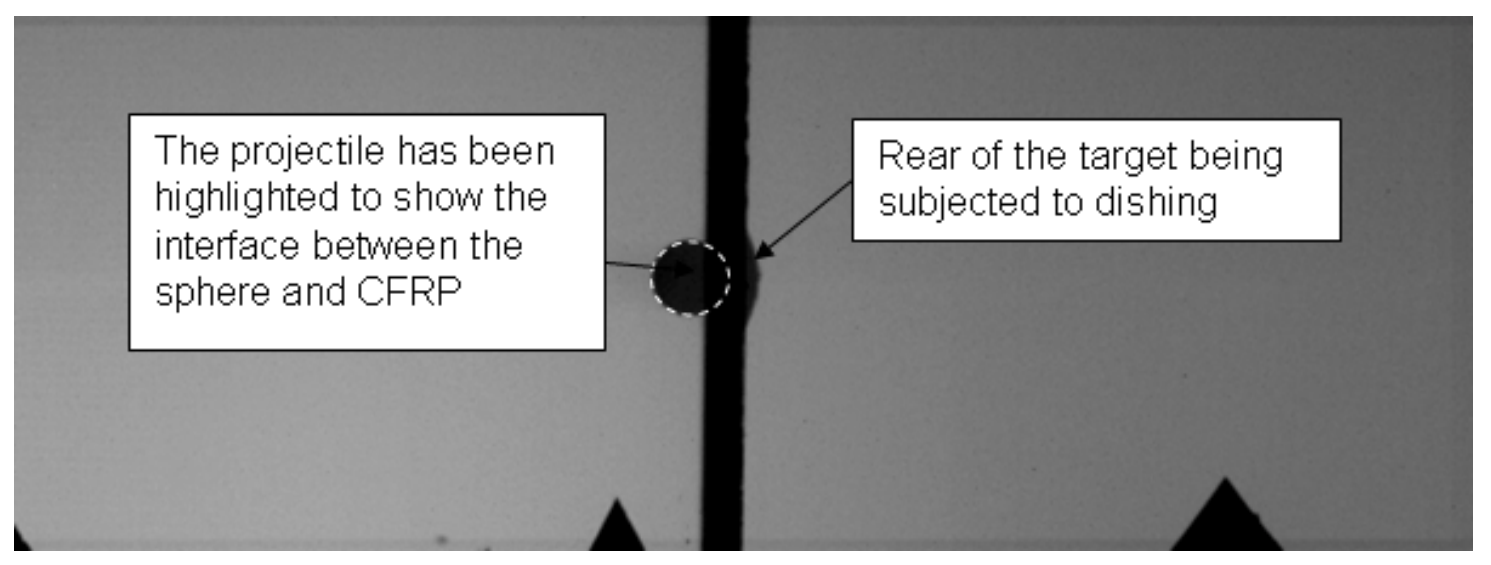

Figure 9 


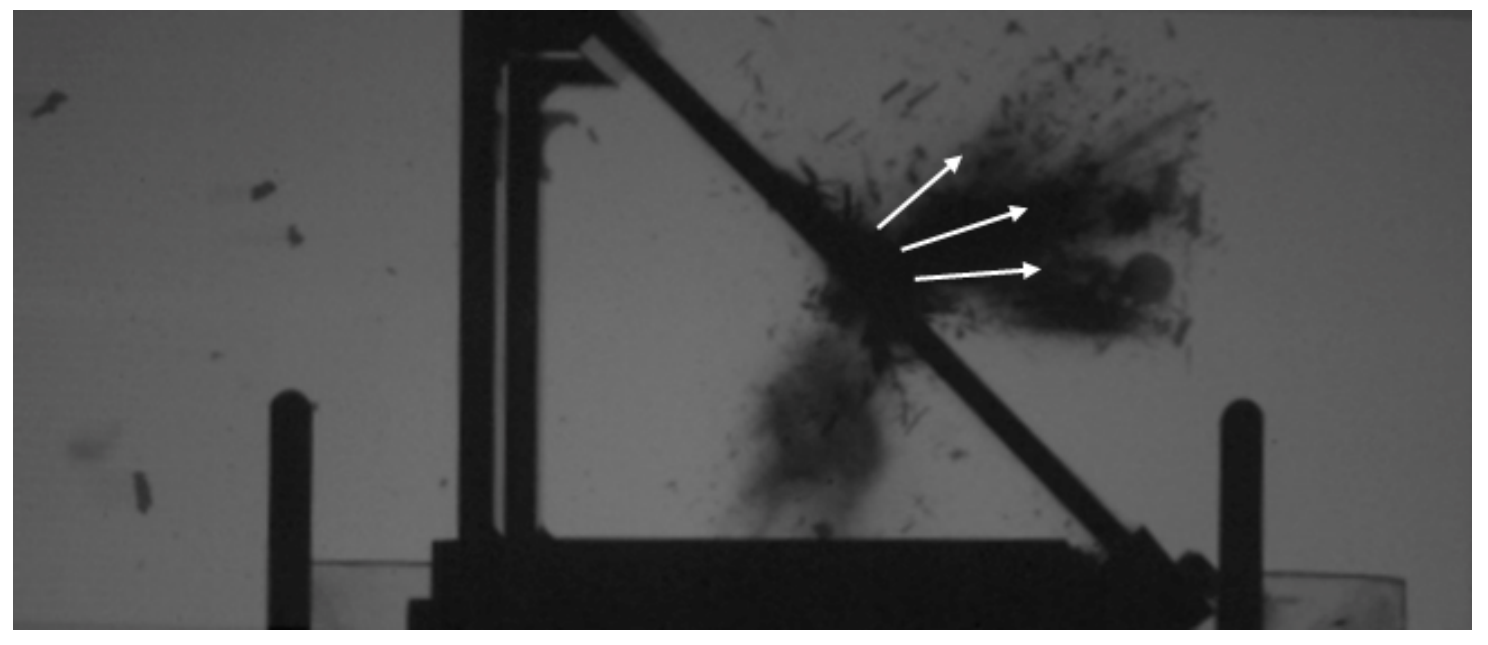

Figure 10 


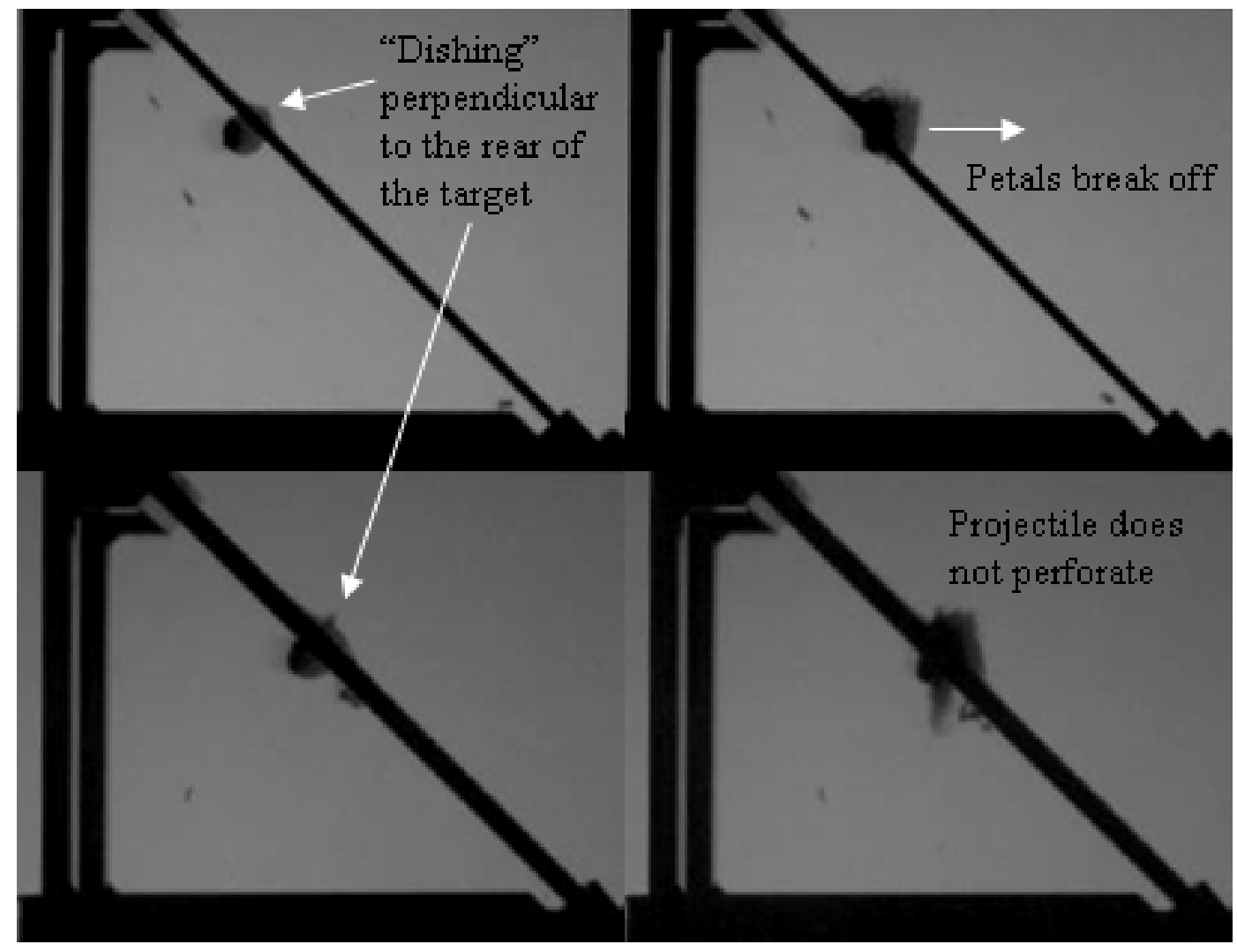

Figure 11 

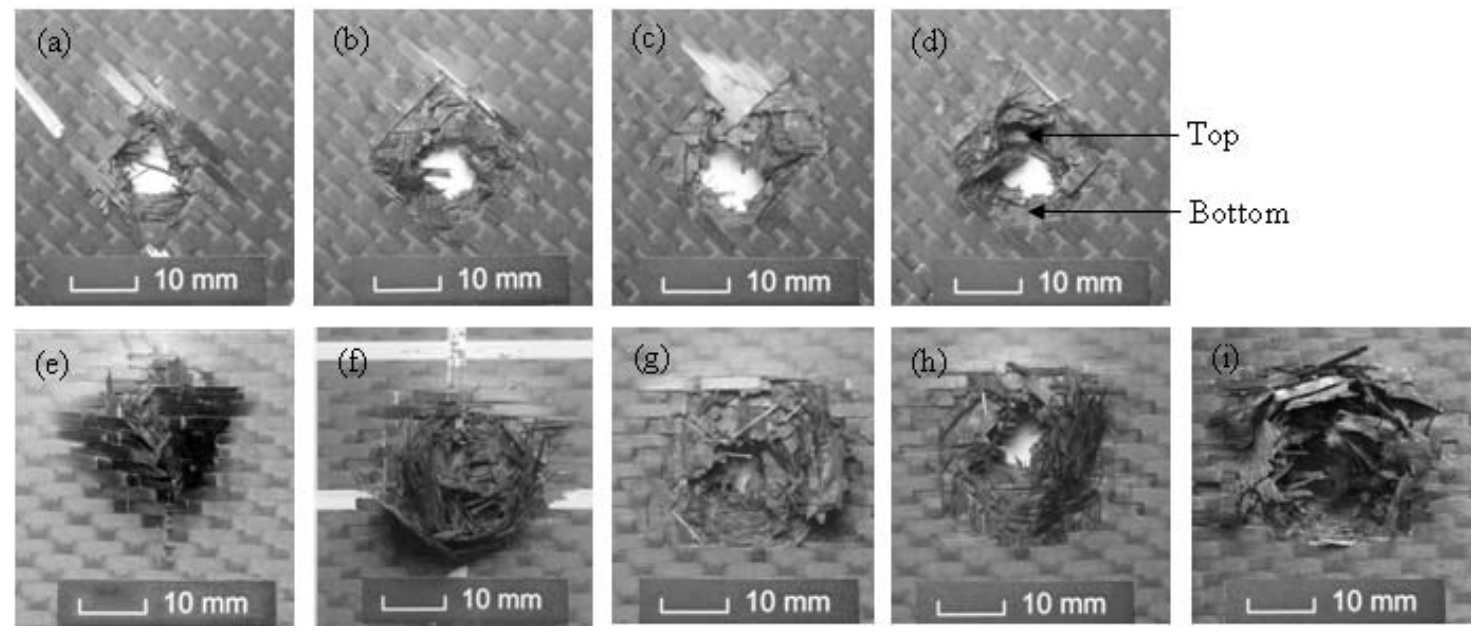

Figure 12 


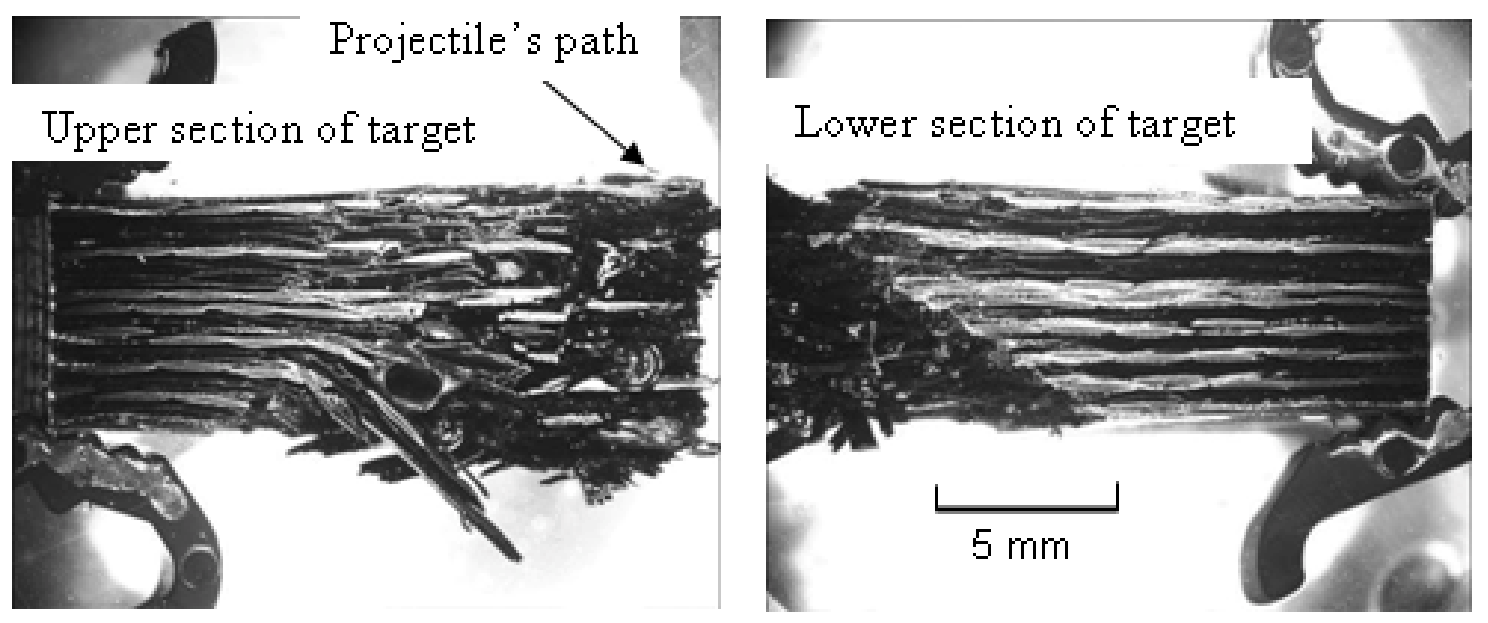

Figure 13 


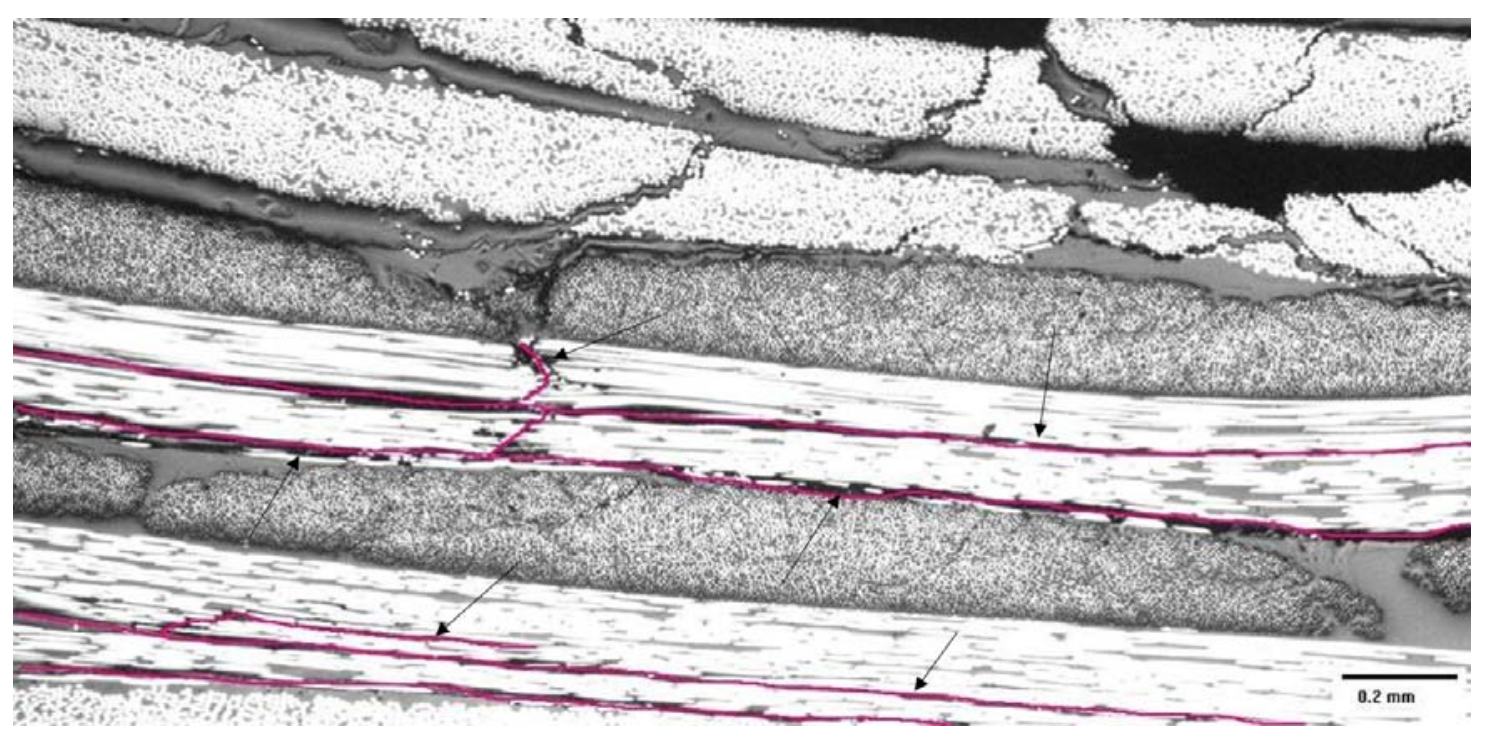

Figure 14 


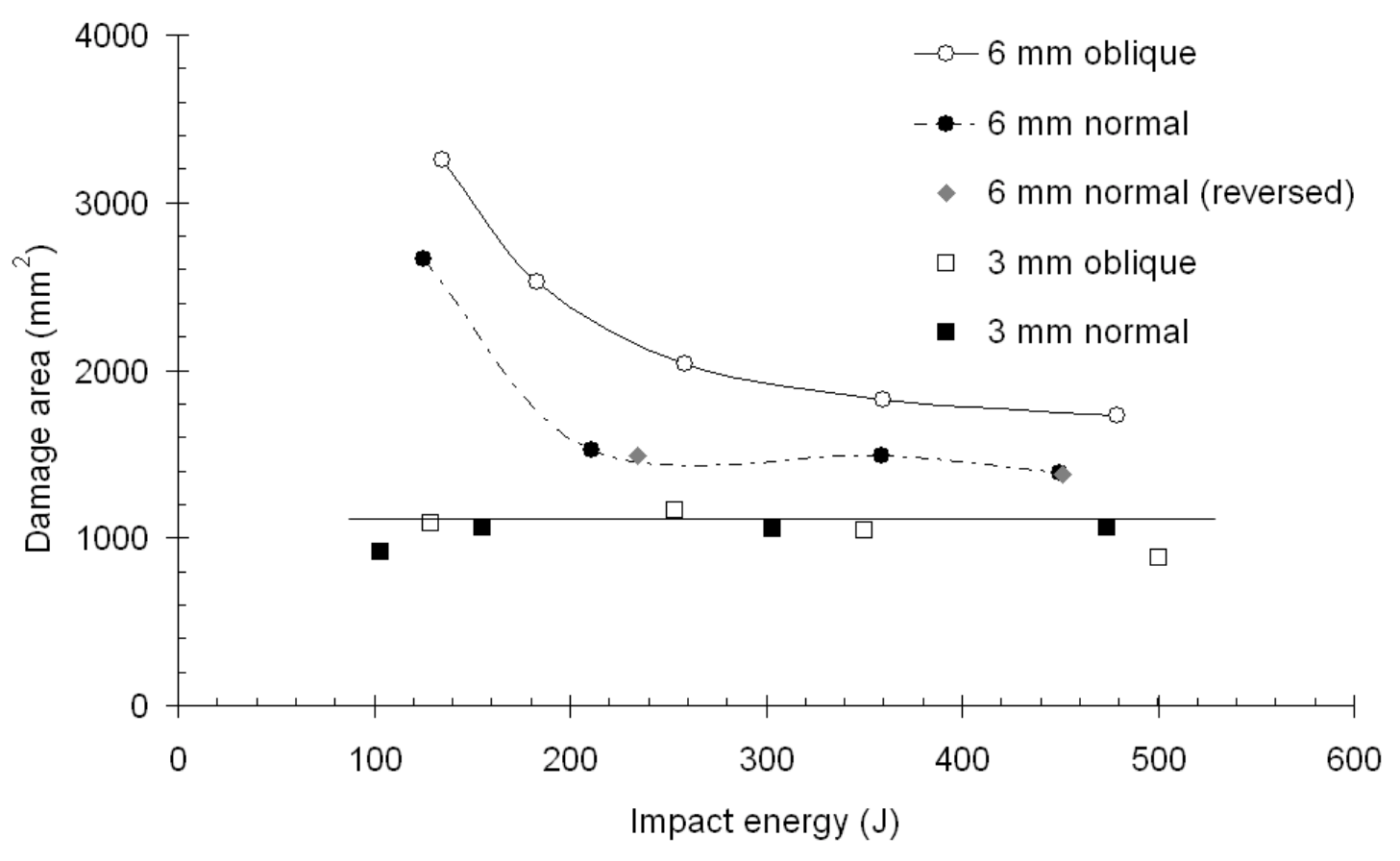

Figure 15 


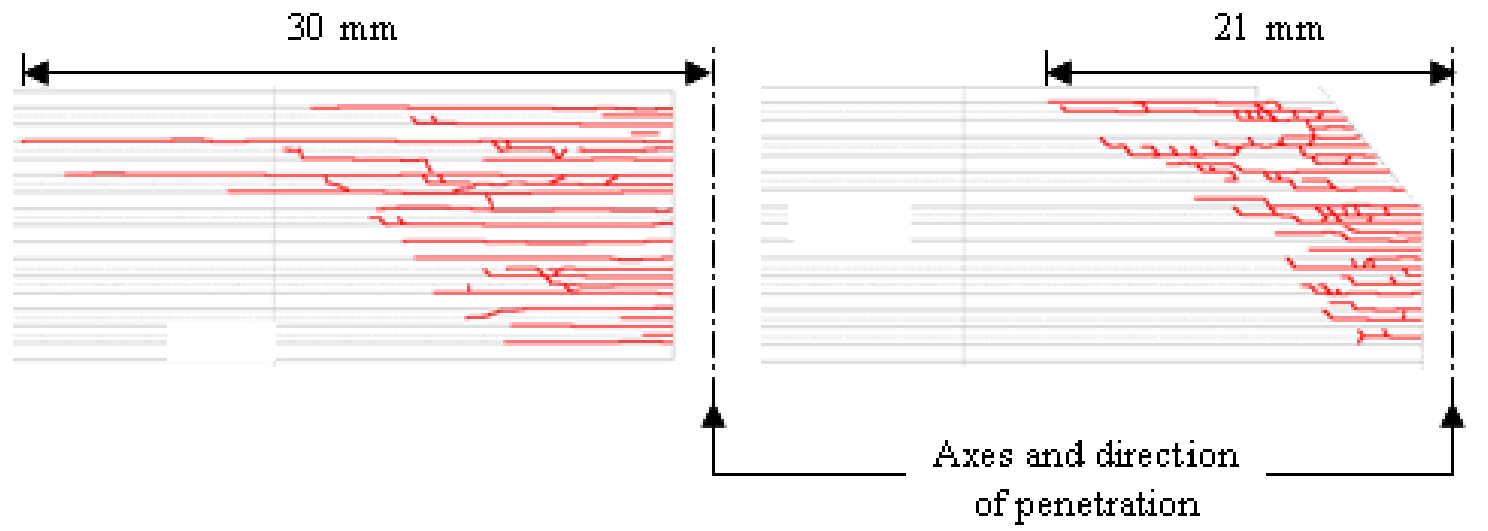

Figure 16 